\title{
Identification and expression analysis of the MSP130-related-2 gene from Hyriopsis cumingii
}

\author{
G.-L. Wang, X.-L. Xia, X.-L. Li, F.-H. He and J.-L. Li \\ Key Laboratory of Freshwater Germplasm Resources, \\ Ministry of Agriculture Shanghai Ocean University, Shanghai, China \\ Corresponding author: J.-L. Li \\ E-mail: j11i2009@126.com
}

Genet. Mol. Res. 14 (2): 4903-4913 (2015)

Received June 4, 2014

Accepted November 12, 2014

Published May 11, 2015

DOI http://dx.doi.org/10.4238/2015.May.11.23

\begin{abstract}
MSP130-related-2 is thought to play a role in biomineralization as revealed in Crassostrea gigas and sea urchins. In this study, an MSP130-related-2 gene was isolated from Hyriopsis cumingii (HcMSP130-related-2) and characterized for the first time. The HcMSP130-related-2 cDNA was $2307 \mathrm{bp}$ in length and consisted of a 572-bp 5'-untranslated region (5'-UTR), a 1239-bp open reading frame encoding 430-amino acid residues, and a 439-bp 3'-UTR. The molecular weight of the peptide was predicted to be $48551.3 \mathrm{Da}$, with a theoretical isoelectric point of 4.78 and instability index of 32.74, indicating that the protein is stable. The HcMSP130-related-2 amino acid residues included a signal peptide and several potential $\mathrm{N}$-glycosylation sites. NCBI BLAST analysis indicated that this full-length amino acid sequence showed the highest similarity with HcMSP130-related-2 from C. gigas (45\%) and about 38\% identity with that from SpMSP130-rel-2 and Strongylocentrotus purpuratus. A phylogenetic tree showed that HcMSP130-rel-2 clustered with MSP130 from C. gigas. HcMSP130related-2 was expressed in various tissues, including the mantle, blood, gill, foot, liver, kidney, intestine, and muscle, with the highest
\end{abstract}


transcripts found in the mantle. Quantitative real-time polymerase chain reaction was used to analyze the expression of the HcMSP130related-2 gene in grass carp after inducing shell damage. HcMSP130related-2 expression was upregulated significantly in the mantle within 7 days $(\mathrm{P}<0.05)$ after damage; however, the expression remained unchanged in the adductor muscle tissues $(\mathrm{P}>0.05)$. These data suggest that HcMSP130-related-2 might be involved in shell formation in $H$. cumingii.

Key words: MSP130-related-2 gene; Hyriopsis cumingii; Inductive expression; Shell formation

\section{INTRODUCTION}

The triangle sail mussel (Hyriopsis cumingii) is a freshwater pearl mussel that is distributed mainly in large lakes and rivers (Liu, 1979). This mussel produces pearls of good quality in terms of color, purity, and shape. Since the artificial propagation of $H$. cumingii was achieved in 1979, this species has become the most important mussel for commercial freshwater pearl production, particularly in China. Currently, the annual production of freshwater pearl is 1800 metric tons in China, and this accounts for almost $95 \%$ of the total world output. In China, more than $90 \%$ of Chinese freshwater pearls are produced from the triangle sail mussel (Xu et al., 2011). Pearl production continues to increase but, at the same time, the quality of freshwater pearls is reducing, and one important reason for this is that little is known about the molecular genetic mechanisms underlying pearl growth. Therefore, investigating the genes that are involved in pearl formation is important.

Pearl is a bio-mineral made up of calcareous rods. Scientists have been exploring the mechanical design of bio-minerals for many years (Stephen, 2001), and the mollusk shell, especially the nacre, is a masterpiece of natural design. The pearl consists of 2 layers: one noncalcified and one calcified. The non-calcified layer is composed of organic materials secreted from the mantle. The main component of the calcified layer is calcium carbonate, calcite, or aragonite (Lowenstaum and Weiner, 1989). Growth of the crystal is strictly regulated throughout mussel development, and various experimental systems have indicated that the proteins associated with shell formation differ on the basis of the genetic background of each particular species. A wide variety of bio-minerals play a key role in regulating the growth, shape and physical properties of materials, such as shells and pearls (Butler, 1998; Wilt, 1999; Fincham et al., 1999; Myllyharju and Kivirikko, 2001; Wang, et al., 2012).

MSP130-related-2 was identified in the sea urchin, Strongylocentrotus purpuratus. Two new bio-mineralization-related proteins related to the primary mesenchyme cell (PMC)specific cell surface glycoprotein MSP130 (MSP130-related-1 and MSP130-related-2) were identified by analyzing a large database of gene products expressed by PMCs (Illies et al., 2002). Seven genes similar to MSP130 were identified. These included the 3 previously indentified MSP130 genes plus 4 others (Livingston et al., 2006). The cell surface protein MSP130 plays a role in bio-mineralization, and it is expressed specifically in calcified tissues of both the embryo and adult (Leaf et al., 1987; Drager et al., 1989). MSP130 was identified in Crassostrea gigas (Zhang et al., 2012). It contains a signal sequence, 2 glycine-rich do- 
mains, and a C-terminal glycosylphosphatidyl inositol (GPI) anchor (Parr et al., 1990). There is evidence that the N-linked oligosaccharide chain on MSP130 could bind divalent cations, including $\mathrm{Ca}^{2+}$ (Farach-Carson et al., 1989). A monoclonal antibody (1223) that recognizes this oligosaccharide chain blocks the uptake of radiolabeled calcium and the formation of spicules by cultured micromeres (Carson et al., 1985). On the basis of these findings, we suggest that MSP130 sequesters $\mathrm{Ca}^{2+}$ ions from the blastocoel fluid and facilitates the uptake into PMCs. The SpMSP130-related-2 protein is similar to MSP130. Like SpMSP130, SpMSP130related-2 contains a signal sequence, a C-terminal GPI anchor domain, and several potential $\mathrm{N}$-glycosylation sites. Thus, MSP130-related-2 is thought to play a role in bio-mineralization as well. This study investigated the MSP130-related-2 gene in H. cumingii.

MSP130-related-2 was cloned from $H$. cumingii by using a defined expressed sequence tag. To further investigate the role of MSP130-related-2, we characterized the gene and determined its potential physiological functions by assessing tissue-specific expression and expression in response to shell damage. Quantitative real-time polymerase chain reaction (qRT-PCR) data indicated that HcMSP130-related-2 might function in shell formation in H. cumingii.

\section{MATERIAL AND METHODS}

\section{Animal treatment and total RNA extraction}

Adult $H$. cumingii individuals of the same age were cultured separately by the WeiWang Company of Jin-Hua (Zhejiang Province, China). Animals were raised at $28^{\circ} \mathrm{C}$ in $400-\mathrm{L}$ aerated aquaria for 2 weeks before experimentation and fed green algae. The mantle, blood, liver, gill, kidney, intestine, foot, and adductor muscle tissues were collected from each of 3 healthy mussels, and total RNA was isolated from these tissues for qRT-PCR. In addition, 54 healthy mussels were used in a shell damage experiment, in which the shell of half of the mussels was damaged according to a published method with some modifications (Mount et al., 2004). A V-shaped notch was cut into the shell margin close to the adductor muscle of the mussels, and then they were divided into 9 groups at random with each group containing 3 individuals. At 2, 6, 12, 24, and $48 \mathrm{~h}$ and 4, 7, 15, and 30 days after injury, 3 mussels were selected from each group. About $1 \mathrm{~cm}^{2}$ of the mantle tissue around the cut was collected. Meanwhile, the mantles of 3 individuals whose shell was not damaged were sampled as described above, and these mussels acted as controls for each group. The mantle and adductor muscle samples were collected from each mussel. All tissues were frozen in liquid nitrogen and then kept at $-80^{\circ} \mathrm{C}$. Total RNA was isolated using the RNAiso Plus (TaKaRa, Japan), incubated with RNase-free gDNA Eraser (TaKaRa), and stored at $-80^{\circ} \mathrm{C}$.

\section{Cloning the full-length cDNA of MSP130-related-2}

A 606-bp fragment of MSP130-related-2 was obtained from a normalized full-length cDNA library of mantle tissues of $H$. cumingii (Bai et al., 2009), and this was used to clone the full-length cDNA of MSP130-related-2 by rapid amplification of cDNA ends (RACE) by using the SMART RACE cDNA Amplification Kit (5'-RACE; Clontech, USA) and RNA PCR Kit (AMV) Ver. 3.0 (3'-RACE; TaKaRa) according to manufacturer instructions. RACE PCR was performed using primer sets designed to the adapter sequences of the kit mentioned above 
and gene-specific primers that had been designed against the cloned PCR fragments (Table 1). The 5'-RACE reactions were carried out in $25-\mu \mathrm{L}$ reaction volumes containing 17.25 $\mu \mathrm{L}$ PCR grade water, $2.5 \mu \mathrm{L} 10 \mathrm{X}$ Advantage $2 \mathrm{X}$ PCR buffer, $0.5 \mu \mathrm{L} 50 \mathrm{X}$ dNTP Mix $(10 \mathrm{mM}), 0.5 \mu \mathrm{L}$ 50X Advantage 2 polymerase mix, $1.25 \mu \mathrm{L}$ 5'-RACE-Ready cDNA, $2.5 \mu \mathrm{L} 10 \mathrm{X}$ Universal Primer A mix $(10 \mu \mathrm{M})$, and $0.5 \mu \mathrm{L}$ gene-specific primer $(10 \mu \mathrm{M})$. PCR was performed under the following conditions: $94^{\circ} \mathrm{C}$ for $30 \mathrm{~min} ; 5$ cycles of $94^{\circ} \mathrm{C}$ for $30 \mathrm{~s}$ and $72^{\circ} \mathrm{C}$ for $3 \mathrm{~min} ; 5$ cycles of $94^{\circ} \mathrm{C}$ for $30 \mathrm{~s}, 70^{\circ} \mathrm{C}$ for $30 \mathrm{~s}$ and $72^{\circ} \mathrm{C}$ for $3 \mathrm{~min}$; and 37 cycles of $94^{\circ} \mathrm{C}$ for $30 \mathrm{~s}, 68^{\circ} \mathrm{C}$ for $30 \mathrm{~s}$, and $72^{\circ} \mathrm{C}$ for $3 \mathrm{~min}$; and $72^{\circ} \mathrm{C}$ for $10 \mathrm{~min}$. The $3^{\prime}-\mathrm{RACE}$ reactions were carried out in a $50-\mu \mathrm{L}$ reaction volume containing $2.0 \mu \mathrm{L}$ 3'-RACE-Ready cDNA, $8 \mu \mathrm{L} 1 \mathrm{X}$ cDNA Dilution Buffer II, $10 \mu \mathrm{M} 2 \mu \mathrm{L}$ gene-specific primer, $10 \mu \mathrm{M} 2 \mu \mathrm{L}$ 3'-RACE Outer Primer, $4 \mu \mathrm{L}$ 10X LA PCR Buffer II ( $\mathrm{Mg}^{2+}$ free), $25 \mu \mathrm{M} 3 \mu \mathrm{L} \mathrm{MgCl}_{2}, 5 \mathrm{U} / \mu \mathrm{L} 0.25 \mu \mathrm{L}$ TaKaRa LA Taq, and $28.75 \mu \mathrm{L}$ $\mathrm{dH}_{2} \mathrm{O}$ under the following conditions: $94^{\circ} \mathrm{C}$ for $3 \mathrm{~min} ; 5$ cycles of $94^{\circ} \mathrm{C}$ for $30 \mathrm{~s}, 52^{\circ} \mathrm{C}$ for $30 \mathrm{~s}$, and $72^{\circ} \mathrm{C}$ for $2 \mathrm{~min} ; 30$ cycles of $94^{\circ} \mathrm{C}$ for $30 \mathrm{~s}, 50^{\circ} \mathrm{C}$ for $30 \mathrm{~s}$, and $72^{\circ} \mathrm{C}$ for $2 \mathrm{~min}$; and finally $72^{\circ} \mathrm{C}$ for $10 \mathrm{~min}$. The PCR product was ligated into PMD19-T vector (TaKaRa), transformed into competent Escherichia coli DH5 $\alpha$ cells (Tiangen, China), seeded on Luria-Bertani agar plates (containing ampicillin, isopropylthio- $\beta$-galactoside, and X-gal), and incubated overnight at $37^{\circ} \mathrm{C}$. Positive clones containing the insert of the expected size were identified by colony PCR. Next, 4 of the positive clones were picked and sequenced on an ABI PRISM 3730 Automated Sequencer by using Big-Dye terminator v3.1 (Applied Bio-Systems, USA).

\section{Sequence analysis}

The open reading frame (ORF) of MSP130-related-2 cDNA was determined using ORF Finder (http://www.ncbi.nlm.nih.gov/projects/gorf/). The physical parameters of the amino acid sequence were predicted using the Protparam program (http://www.expasy.org/ tools/protparam.html). The watershed was predicted using the ProtScale program (http:// www.expasy.ch/tools/protscale.html). The putative amino acid sequence was analyzed for the presence of signal peptides by using the SignalP3.0 Server (http://www.cbs.dtu.dk/services/ SignalP/; Bendtsen et al., 2004). Nucleotide and amino acid sequence identities and the prediction of conserved domains in the peptide were performed using the BLAST program (GenBank, NCBI). A phylogenetic tree was constructed using the deduced full-length amino acid sequence by the neighbor joining (NJ)-embedded algorithm and maximum likelihood method in the Mega 5.0 program. The reliability of the estimated tree was evaluated using the bootstrap method with 1000 pseudo-replications. The accession numbers of the primer sequences used in this analysis are listed in Table 1.

\begin{tabular}{|c|c|c|}
\hline Primer name & Primer sequence $\left(5^{\prime}-3^{\prime}\right)$ & Application \\
\hline MSP130-related-2-GSP for 5'-RACE & GCGACCACCCACGACTATTTTGTGAACT & 5'-RACE PCR \\
\hline 5'-RACE-UPM & CTAATACGACTCACTATAGGGC & 5'-RACE PCR \\
\hline MSP130-related-2-GSP for 3'-RACE & CCCGCAATCTGACTAACACT & 3'-RACE PCR \\
\hline 3'race-Primer M4 & GTCGTGACTGGGAAAAC & 3'-RACE PCR \\
\hline MSP130-related-2-qRT-F & CGGCTTCAAGGATTGGTCA & Primers for $\mathrm{qPCR}$ \\
\hline MSP130-related-2-qRT-R & GCGTCTCCTTCATTGGCAG & Primers for qPCR \\
\hline$\beta$-actin-F & ACGGATAACACAAGGAAAGGAAAC & Housekeeping gene \\
\hline$\beta$-actin-R & ATGGATGGAAACACGGCTCT & Housekeeping gene \\
\hline
\end{tabular}




\section{qRT-PCR analysis}

Mantle, blood, liver, gill, kidney, intestine, adductor muscle, and foot tissues were collected and used to assess tissue expression by qRT-PCR (mantle; blood; gill; foot; liver; kidney; intestines; muscle). Expression of MSP130-related-2 after shell damage was investigated in the mantle and adductor muscle tissue of adult $H$. cumingii individuals, and this was performed using a CFX96 Real-Time PCR System (Bio-Rad). Total RNA was isolated after shell damage as described above. About $1 \mu \mathrm{g}$ RNA from each sample was reverse transcribed using the Prime-Script RT reagent kit with the gDNA Eraser (TaKaRa). The first-strand cDNA was subsequently used as the template for PCR by using the primer pair listed in Table 1 . $\beta$-actin was amplified to serve as an internal control for cDNA normalization (accession No. HM045420). qRT-PCR was performed in $20-\mu \mathrm{L}$ reactions consisting of $1 \mu \mathrm{L} 50 \mathrm{ng}$ cDNA, 8.2 $\mu \mathrm{L}$ nuclease-free water, $10 \mu \mathrm{L} 2 \mathrm{X}$ SYBR Premix Ex-Taq ${ }^{\mathrm{TM}}$ (TaKaRa), and $10 \mu \mathrm{M} 0.4 \mu \mathrm{L}$ of each gene-specific primer. The PCR cycling conditions were $95^{\circ} \mathrm{C}$ for $30 \mathrm{~s} ; 40$ cycles of $95^{\circ} \mathrm{C}$ for $5 \mathrm{~s}$, and $60^{\circ} \mathrm{C}$ for $34 \mathrm{~s}$; followed by dissociation curve analysis at $95^{\circ} \mathrm{C}$ for $15 \mathrm{~s}, 60^{\circ} \mathrm{C}$ for $60 \mathrm{~s}$, and $95^{\circ} \mathrm{C}$ for $15 \mathrm{~s}$ to verify the amplification of a single product. The threshold cycle $(\mathrm{Ct})$ value was determined using the 7500 v2.0 software, and data were exported to Microsoft Excel for subsequent analysis, where the relative expression ratios of the target gene in treated and control groups were calculated by using the $2^{-\Delta \Delta \mathrm{Ct}}$ method. Each experiment was repeated three times.

\section{Statistical analysis}

Data from the qRT-PCR experiments are reported as means \pm SE. Differences among groups were analyzed in SPSS 19.0 by using one-way analysis of variance tests with the post hoc Dunnett T3 test. Significance was accepted at the level of $\mathrm{P}<0.05$.

\section{RESULTS}

\section{Cloning and sequence analysis of $H$. cumingii MSP130-related-2 cDNA}

A full-length cDNA of MSP130-related-2 from $H$. cumingii was obtained from a normalized full-length cDNA library and 5'-RACE and 3'-RACE experiments. The HcMSP130related-2 cDNA was $2307 \mathrm{bp}$ in length, and this consisted of a 572-bp 5'-untranslated region (5'-UTR), a 1239-bp ORF encoding 430-amino acid residues, and a 439-bp 3'-UTR. The molecular weight of the peptide is predicted to be $48551.3 \mathrm{Da}$, with a theoretical isoelectric point of 4.78 and instability index of 32.74 , which indicates that the protein is stable. The protein has no obvious watershed sites and does not exist across any membrane. NCBI BLAST analysis revealed that the deduced amino acid sequence of HcMSP130-related-2 shared $45 \%$ identity with MSP130 of C. gigas and about 38\% identity with SpMSP130-rel-2 of $S$. purpuratus. This sequence homology is relatively low, which suggests that MSP130related-2 has not been highly conserved during evolution. Thus, focusing on its potential functional domains, evolutionary relationships, and biological roles is important (Zhou et al., 2011). Similar to SpMSP130-related-2, HcMSP130-related-2 is predicted to contain a signal sequence and several potential N-glycosylation sites (Figure 1), but it lacks the 
extended glycine-rich domain found in MSP130 and the C-terminal GPI anchor found in the $S$. purpuratus MSP130-related-2, which is a valuable model system for analyzing the cellular and molecular regulation of bio-mineralization (Decker and Lennarz, 1988; Benson and Wilt, 1992; Ettensohn et al., 1997; Wilt, 1999). A phylogenetic tree was constructed using the neighbor joining and maximum likelihood methods (Figure 2). The data showed that the MSP130s from 3 species of sea urchins, Hyriopsis erythrogramma, Hyriopsis tuberculata, and S. purpuratus cluster together, and then with SpMSP130-rel-1 and SpMSP130-related-2 of S. purpuratus. The HcMSP130-rel-2 in this study clustered with the MSP130 of C. gigas, and then separated from sea urchins. This indicates that HcMSP130-rel-2 belongs to the MSP130 family.

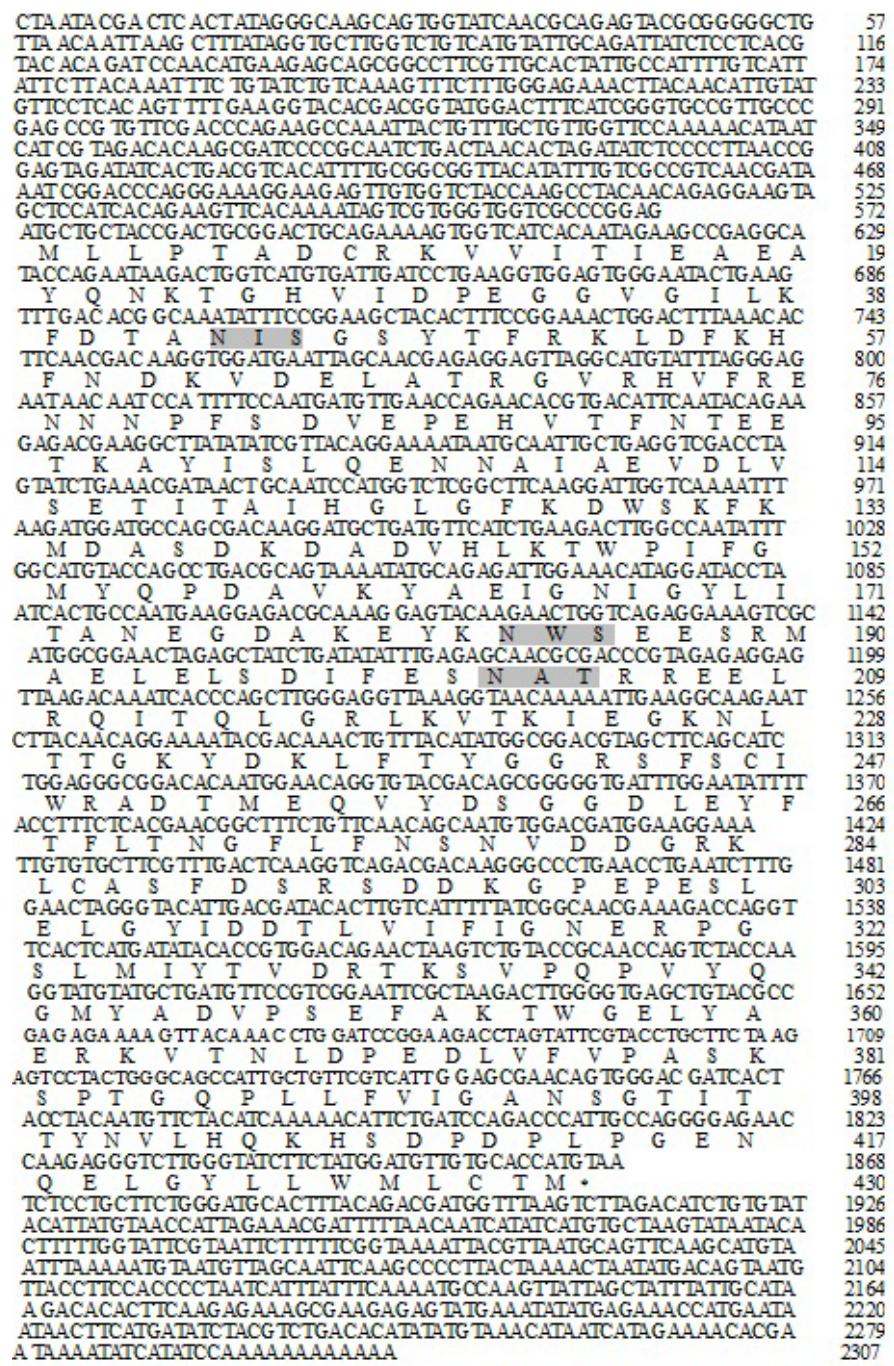

Figure 1. Nucleotide and deduced amino acid sequences of the MSP130-related-2 cDNA in the triangle sail mussel (Hyriopsis cumingii). The $\mathrm{N}$-glycosylation sites are shaded in gray. 


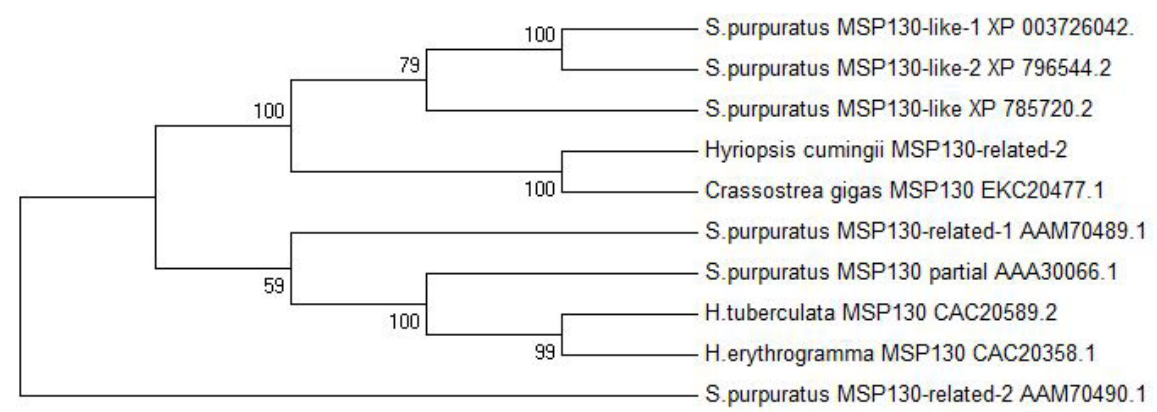

Figure 2. Neighbor-joining (NJ) phylogenetic tree. Amino acid sequences were analyzed using the NJ method in the Mega 5.0 program. The protein sequences used for phylogenetic analysis were as follows: HcMSP130-rel-2 clustered with the MSP130 from Crassostrea gigas, the MSP130 from three species of sea urchins, Hyriopsis erythrogramma, H. tuberculata and Strongylocentrotus purpuratus, clustered together, then with SpMSP130-rel-1 and SpMSP130-related-2 of S. purpuratus clustered.

\section{Constitutive expression of the HcMSP130-related-2 gene in different tissues}

To gain insight into the possible physiological functions of HcMSP130-related-2, we analyzed the expression of HcMSP130-related-2 in different tissues by using qRT-PCR. The HcMSP130-related-2 mRNA was detected in the mantle, blood, gill, foot, liver, kidney, intestine, and muscle tissues (Figure 3). Although HcMSP130-related-2 was expressed in all tissues, its expression levels varied across these tissues. HcMSP130-related-2 showed significantly higher expression levels in the mantle than in other tissues $(\mathrm{P}<0.05)$ and the lowest in blood. There were no statistically significant differences among its expression in gill, foot, liver, kidney, intestine, and muscle. This indicates that HcMSP130-related-2 might play an important role in bio-mineralization, including pearl production and nacreous shell growth.

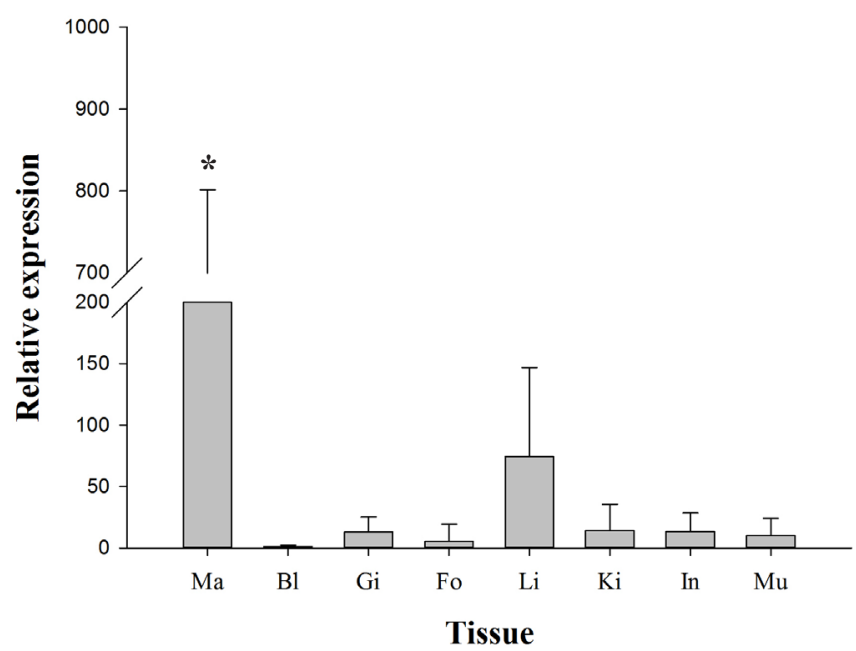

Figure 3. Relative expression levels of the HcMSP130-rel-2 gene. Amounts of mRNA levels obtained by quantitative real-time PCR (qRT-PCR) are indicated. The relative expression of each particular gene transcript was calculated based on the standard curve and normalized to the $\beta$-actin mRNA level. *Indicates a significant difference $(\mathrm{P}<0.05)$. $\mathrm{Ma}=$ mantle; $\mathrm{Bl}=$ blood $; \mathrm{Gi}=$ gill; $\mathrm{Fo}=$ foot $; \mathrm{Li}=$ liver; $\mathrm{Ki}=$ kidney; $\mathrm{In}=$ intestines; $\mathrm{Mu}=$ muscle . 


\section{Inductive expression of HcMSP130-related-2 after shell damage}

Inductive expression of HcMSP130-related-2 was investigated after shell damage. After shell damage to $H$. cumingii, the expression of MSP130-related-2 was investigated in the mantle and muscle. During the experiment, expression of $\beta$-actin was almost stable in each of the tissues under examination, which excluded the possibility that any differences in HcMSP130-related-2 expression were caused by variations in the input RNA, efficiency of cDNA synthesis, or any other PCR artifact. In the mantle, the expression of MSP130-related-2 was upregulated and then decreased (Figure 4). MSP130-related-2 transcript levels in the mantle were upregulated significantly 7 days after shell damage $(\mathrm{P}<0.05)$; thus, the expression had changed in response to this injury. However, no significant difference in expression was detected in the adductor muscles after shell damage $(\mathrm{P}>0.05)$.

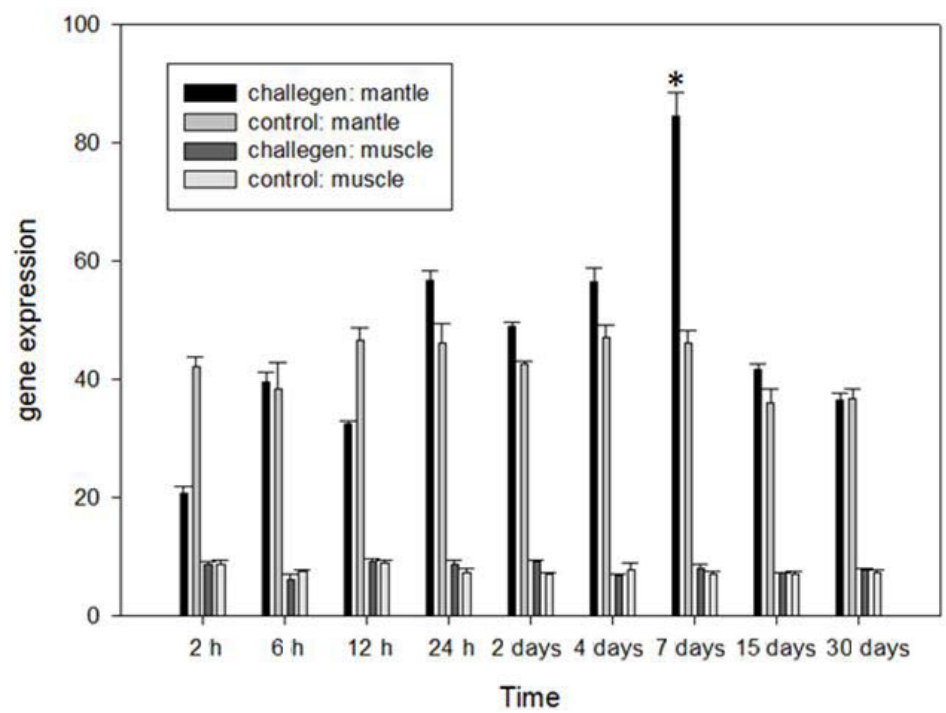

Figure 4. Quantification by qRT-PCR of the MSP130-related-2 mRNA in the mantle and adductor muscle after shell damage. The $\mathrm{X}$-axis is the time after injury. Transcript quantities were normalized to $\beta$-actin mRNA. The expression of HcMSP130-related-2 was up-regulated significantly in the mantle 7 days after damage $(\mathrm{P}<0.05)$. *Indicates a significant difference.

\section{DISCUSSION}

In this study, a MSP130-related-2 was cloned and characterized for the first time in $H$. cumingii. Sequence alignment revealed that the deduced amino acid sequence of MSP130-related-2 shared approximate identity with MSP130 of C. gigas and 38\% identity with MSP130related-2 of S. purpuratus. The HcMSP130-rel-2 in this study clustered with the MSP130 in C. gigas. The HcMSP130-related-2 peptide was predicted to contain a signal sequence and several potential N-glycosylation sites. MSP130-related-2 has been identified previously in the sea urchin and is known to be related to the PMC-specific cell surface glycoprotein MSP130. The primary sequences of MSP 130 proteins offer a few clues concerning their possible functions, but relatively little is known about MSP130-related-2 proteins. There is evidence that N- 
linked oligosaccharides on MSP130 bind $\mathrm{Ca}^{2+}$ and, while the precise role of MSP130 remains unclear, the specific expression of this protein by PMCs in calcified tissues of the adult and its calcium-binding properties indicate strongly that it has a role in bio-mineralization. The carbohydrate epitope borne by SpMSP130 is recognized by a monoclonal antibody and is shared by 2 other PMC-specific GPI-linked cell surface proteins. These proteins may be SpMSP130related-1 and SpMSP130-related-2 (Kabakoff et al., 1992). MSP130-related-2 probably contributes to this complex pattern and plays a role in bio-mineralization.

MSP130-related-2 can regulate the process of bio-mineralization in the endoskeleton of the sea urchin larva (Illies et al., 2002). In this study, HcMSP130-related-2 was detected in the mantle, blood, gill, foot, liver, kidney, intestine, and muscle tissues, with the greatest expression detected in the mantle $(\mathrm{P}<0.05)$ and at very low levels in the other tissues, especially in blood. The mantle is a key tissue involved in bio-mineralization (Beirao and Sorenson, 1985; Beirao and Nascimento, 1989). The epithelial cells of the inner and middle folds communicate directly with the ambient medium and are responsible for absorbing $\mathrm{Ca}^{2+}$ from the sea water (Simkiss and Wilbur, 1989). The mantle is also considered to be an important tissue for calcium storage (Pekkarinen and Valovirta, 1997). The shell and nacre of the mollusc are bio-mineralization products for which $\mathrm{Ca}^{2+}$ is one of the most important components. The high expression of HcMSP130-related-2 in the mantle indicates that this gene might participate in $\mathrm{Ca}^{2+}$ absorption and storage and is involved in bio-mineralization.

qRT-PCR was used to quantify HcMSP130-related-2 expression kinetics after shell damage. The HcMSP130-related-2 transcript levels increased with time and, 7 days after induction of injury, the transcript levels were the greatest in the mantle, while they were lowest at $2 \mathrm{~h}$ (Figure 4). HcMSP130-related-2 expression was significantly upregulated in the mantle 7 days after shell damage $(\mathrm{P}<0.05)$. In contrast, MSP130-related-2 transcript levels in the muscle decreased with time but not significantly $(\mathrm{P}>0.05)$. The mantle is positively involved in the regulation and maintenance of the extrapallial fluid where calcium carbonate is crystallized, suggesting that the synthesis of matrix proteins present in the calcified layer of the shell depends on the mantle (Gong et al., 2008). HcMSP130-related-2 expression before $24 \mathrm{~h}$ was probably high due to stress response, and then the expression levels increased significantly. The significant change of HcMSP130-related-2 expression in the mantle after shell damage indicates that this gene might play a role in shell formation in H. cumingii. HcMSP130-related-2 belongs to the MSP130 family, and these cell surface proteins play key roles in bio-mineralization. MSP130 is expressed specifically in calcified tissues in both the embryo and adult (Drager et al., 1989; Leaf et al., 1987). According to the results of the shell damage tests, we propose that MSP130related-2 has similar functions to MSP130 and is involved in the bio-mineralization of the shell in $H$. cumingii and plays a role in calcium metabolism. The pearl and shell of $H$. cumingii are the result of calcium metabolism; thus, we speculate that HcMSP130-related-2 plays a role in pearl formation. In this study, HcMSP130-related-2 expression profiles in response to shell damage were determined only in the mantle and adductor muscle of adult $H$. cumingii individuals. Our data initially suggest that HcMSP130-related-2 plays a role in the formation of the shell, but this requires further validation. Whether the contribution of HcMSP130-related-2 to pearl production is the same as its role in shell growth also requires further investigation.

In conclusion, HcMSP130-related-2 was cloned and characterized for the first time from $H$. cumingii. The present study is an initial investigation identifying the function of HcMSP130-related-2 in H. cumingii. Further studies concerning the role of MSP130-related-2 in the formation of pearl is warranted. 


\section{ACKNOWLEDGMENTS}

Research supported by grants from the National Natural Science Foundation of China (\#31101939), the Innovation Program of Shanghai Municipal Education Commission (\#13ZZ128), and the Shanghai Universities Knowledge Service Platform (\#ZF1206).

\section{REFERENCES}

Bai Z, Yin Y, Hu S, Wang G, et al. (2009). Identification of genes involved in immune response, microsatellite, and SNP markers from expressed sequence tags generated from hemocytes of freshwater pearl mussel (Hyriopsis cumingii). Mar. Biotechnol. 11: 520-530.

Beirao PS and Sorenson AL (1985). Two types of action potentials in a secretory epithelium of a clam mantle. J. Exp. Biol. 121: 179-195.

Beirao PS and Nascimento HM (1989). Sodium and calcium-sependent mechanisms in the action potential of the secretory epithelium of a clam mantle. J. Mol. Biol. 145: 395-402.

Bendtsen JD, Nielsen H, von Heijne G and Brunak S (2004). Improved prediction of signal peptides: SignalP 3.0. J. Mol. Biol. 340: 783-795.

Benson SC and Wilt F (1992). Calcification of Spicules in the Sea Urchin Embryo. In: Calcification in Biological Systems (Bonucci E, ed.). CRC Press, Ann Arbor, 157-178.

Butler WT (1998). Dentin matrix proteins. Eur. J. Oral Sci. 106 (Suppl 1): 204-210.

Carson DD, Farach MC, Earles DS, Decker GL, et al. (1985). A monoclonal antibody inhibits calcium accumulation and skeleton formation in cultured embryonic cells of the sea urchin. Cell 41: 639-648.

Decker GL and Lennarz WJ (1988). Skeletogenesis in the sea urchin embryo. Development 103: 231-247.

Drager BJ, Harkey MA, Iwata M and Whiteley AH (1989). The expression of embryonic primary mesenchyme genes of the sea urchin, Strongylocentrotus purpuratus, in the adult skeletogenic tissues of this and other species of echinoderms. Dev. Biol. 133: 14-23.

Ettensohn CA, Guss KA, Hodor PG and Malinda KM (1997). The Morphogenesis of the Skeletal System of the Sea Urchin Embryo. In: Progress in Developmental Biology. Vol. VIII. Reproductive Biology of Invertebrates, Wiley, New York, 225-265.

Farach-Carson MC, Carson DD, Collier JL, Lennarz WJ, et al. (1989). A calcium-binding, asparagine-linked oligosaccharide is involved in skeleton formation in the sea urchin embryo. J. Cell Biol. 109: 1289-1299.

Fincham AG, Moradian-Oldak J and Simmer JP (1999). The structural biology of the developing dental enamel matrix. J. Struct. Biol. 126: 270-299.

Gong N, Li Q, Huang J, Fang Z, et al. (2008). Culture of outer epithelial cells from mantle tissue to study shell matrix protein secretion for biomineralization. Cell Tissue Res. 333: 493-501.

Illies MR, Peeler MT, Dechtiaruk AM and Ettensohn CA (2002). Identification and developmental expression of new biomineralization proteins in the sea urchin Strongylocentrotus purpuratus. Dev. Genes Evol. 212: 419-431.

Kabakoff B, Hwang SP and Lennarz WJ (1992). Characterization of post-translational modifications common to three primary mesenchyme cell-specific glycoproteins involved in sea urchin embryonic skeleton formation. Dev. Biol. 150: 294-305.

Leaf DS, Anstrom JA, Chin JE, Harkey MA, et al. (1987). Antibodies to a fusion protein identify a cDNA clone encoding msp130, a primary mesenchyme-specific cell surface protein of the sea urchin embryo. Dev. Biol. 121: 29-40.

Liu YY (1979). Economic Fauna of China (Freshwater mollusk). Science Press, Beijing, 83-84.

Livingston BT, Killian CE, Wilt F, Cameron A, et al. (2006). A genome-wide analysis of biomineralization-related proteins in the sea urchin Strongylocentrotus purpuratus. Dev. Biol. 300: 335-348.

Lowenstaum H and Weiner S (1989). On Bio-Mineralization. Oxford University Press, New York, 326.

Mount AS, Wheeler AP, Paradkar RP and Snider D (2004). Hemocyte-mediated shell mineralization in the eastern oyster. Science 304: 297-300.

Myllyharju J and Kivirikko KI (2001). Collagens and collagen-related diseases. Ann. Med. 33: 7-21.

Parr BA, Parks AL and Raff RA (1990). Promoter structure and protein sequence of msp130, a lipid-anchored sea urchin glycoprotein. J. Biol. Chem. 265: 1408-1413.

Pekkarinen M and Valovirta I (1997). Histochemical and X-mystudies on tissue concretions and shell of Margaritifera margaritifera (Linnaeus). J. Shellfish Res. 16: 169-177.

Simkiss K and Wilbur KM (1989). Biomineralization: Cell Biology and Mineral Deposition. Academic Press, New York.

Genetics and Molecular Research 14 (2): 4903-4913 (2015)

CFUNPEC-RP www.funpecrp.com.br 
Stephen M (2001). Bio-Mineralization: Principles and Concepts in Bioinorganic Materials, Chemistry. Oxford University Press, Oxford.

Wang GL, Xu B, Bai ZY and Li JL (2012). Two chitin metabolic enzyme genes from Hyriopsis cumingii: cloning, characterization, and potential functions. Genet Mol. Res. 11: 4539-4551.

Wilt FH (1999). Matrix and mineral in the sea urchin larval skeleton. J. Struct. Biol. 126: 216-226.

Xu B, Li J and Wang G (2011). Development and characterization of microsatellite loci in Lamprotula leai, with crossamplification in Hyriopsis cumingii. Conserv. Genet. Resour. 3: 545-547.

Zhang G, Fang X, Guo X, Li L, et al. (2012). The oyster genome reveals stress adaptation and complexity of shell formation. Nature 490: 49-54.

Zhou J, Gao YF, Li L, Zhai HN, et al. (2011). Identification and functional characterization of a putative 17ß-hydroxysteroid dehydrogenase 12 in abalone (Haliotis diversicolor supertexta). Mol. Cell Biochem. 354: 123-133. 